\title{
Hospital Admissions of Cardiovascular Diseases Associated to Air Pollution
}

\author{
${ }^{1 *}$ Marcio Sacramento de Oliveira, ${ }^{2}$ Maria de Fátima Ebole Santana, \\ ${ }^{3}$ Inês Echenique Mattos, ${ }^{4}$ Antônio Ponce de Leon \\ ${ }^{1,2}$ Polytechnic School of Health Joaquim Venancio (EPSJV)/ Oswaldo Cruz Foundation (Fiocruz). \\ Brasil Ave, Manguinhos, Rio de Janeiro, RJ, Brazil. \\ ${ }^{3}$ Inês Echenique Mattos, ENSP/ Oswaldo Cruz Foundation (Fiocruz), 4365 Brasil Ave, Manguinhos, \\ Rio de Janeiro, RJ, Brazil, Zipcode: 21045-900. \\ ${ }^{4}$ IMS, UERJ, Brazil. 524, São Francisco Xavier Ave, Rio de Janeiro, RJ, Brazil.
}

\begin{abstract}
This study analyzed the association between air pollution and Hospital Admissions from Cardiovascular Diseases considering differential susceptibility in the elderly. The authors used daily Hospital Admissions from Cardiovascular Diseases (ICD-10, I00-199), $\mathrm{PM}_{10}, \mathrm{SO}_{2}$, and $\mathrm{O}_{3}$ levels, and meteorological indicators in Volta Redonda, Rio de Janeiro State, Brazil, from January 2002 to December 2006. The association was estimated by Poisson regression using generalized additive models, where the increase in risk of Hospital Admissions from PM10 to lag 3 was 3.84\% (95\% CI 0.40 to 7.40\%; p-value =0.03) in only elderly people. For exposure to $\mathrm{SO}_{2}$ and $\mathrm{O}_{3}$, the risk was not significant neither in the total population and nor in the elderly. The results of this study together the others published in the same territory demonstrate a significant degree of environmental vulnerability and health risk of the local population associated to air pollution.
\end{abstract}

Keywords: Air Pollution; Cardiovascular Diseases; Environment Risk; Hospital Admissions

Abbreviations: relative humidity (RH), Unified Health System (SUS), sulfur dioxide (SO $\left.\mathrm{S}_{2}\right)$, ozone $\left(\mathrm{O}_{3}\right)$, particulate matter with aerodynamic size up to $10 \mu \mathrm{m}\left(P M_{10}\right)$,Expectation Maximization (EM), Generalized Additive Models (GAM), Akaike Information Criterion (AIC), relative risks (\%RR), National Council of Environment(CONAMA), Hospital Admission Orders (OAH), International Statistical Classification of Diseases and Related Health Problems (ICD).

\section{INTRODUCTION}

In many countries of the world, several Epidemiological studies developed provide some evidences of the air pollution have been considered a serious public health problem for some time, acting as an additional health risk factor for humans, animals, and plants.

Air pollution is associated different health outcomes and increased daily air pollution levels, especially in more susceptible population groups like children, elderly, and individuals with cardio respiratory diseases [1, 2, 3].In studies realized in London, was found [4] an association between PM10 and the increase in cardiovascular deaths and admissions of $2.2 \%(95 \% \mathrm{CI}=0.6-3.8 \%)$ and $0.6 \%(95 \% \mathrm{CI}=$ $0.4-1.7 \%)$, respectively.

Cities with a high degree of industrialization, including steel producing plant, intense vehicular flow and rail way transport of ores in the central region, as Volta Redonda city, in Brazil, demonstrate a significant degree of environmental vulnerability and health risk of the local population.

In this scenario, this current study aimed to assess the association between air pollution and Hospital Admissions from Cardiovascular Diseases considering differential susceptibility in the elderly.

\section{Methodology}

This was an ecological time series study conducted in the Volta Redonda city, Rio de Janeiro State, Brazil, from January $1^{\text {st }}, 2002$, to December $31^{\text {st }}, 2006$.

\subsection{Study Area}

Volta Redonda is a mid-sized city located at $22^{\circ} 31^{\prime} 23^{\prime \prime}$ latitude South and $44^{\circ} 06^{\prime} 15^{\prime \prime}$ longitude west. The municipality's total area is $182.8 \mathrm{~km}^{2}$, of which $54 \mathrm{~km}^{2}$ comprise the city limits of the municipal seat. Accompanying the Paraíba do Sul River, which cuts through the city of Volta Redonda from Southwest to East, the urban area is located along the banks of the river on a plain surrounded by hills 
whose altitude varies from 350 meters above sea level along the river to 707 meters at the northeastern tip. The city has a mesothermal climate and high relative humidity $\mathrm{RH}(77 \%)$, even in the winter months, when it varies from $71 \%$ to $72 \%$. The adjusted mean temperature is $21^{\circ} \mathrm{C}$, with a mean annual low of $16.5^{\circ} \mathrm{C}$ and means annual high of $27.8^{\circ} \mathrm{C}$. Mean annual precipitation is $1,377.9$ $\mathrm{mm}$, and January and February are the months with the heaviest rainfall. Considered as the economic center of the SulFluminense mesoregion, the economy of Volta Redonda is anchored in industry activity but beside this profile, there are areas in increasing rise like services and commerce.

\subsection{Health Outcomes and Data Source}

The time series of total hospital admissions was analyzed by the cardiovascular system diseases (ICD10, I00-I99), and stratified in elderly aged 65 or more. Data on hospital admissions to public hospitals and private hospitals insured of the Unified Health System (SUS) were obtained from the SIH-SUS information available at the DATASUS database online database. These databases have information of all hospital admissions according to the SUS recorded in Hospital Admissions Authorizations $(\mathrm{AIH})$, which have the following information that was used: municipality of residence, age, date of admission and principal diagnosis.

\subsection{Environmental Outcomes and Data Source}

Daily records of mean concentrations of particulate matter with aerodynamic size up to $10 \mu \mathrm{m}\left(\mathrm{PM}_{10}\right)$, sulfur dioxide $\left(\mathrm{SO}_{2}\right)$, ozone $\left(\mathrm{O}_{3}\right)$, low temperature, and mean relative humidity $(\mathrm{RH})$ were provided by the Rio de Janeiro State Environment Institute (INEA). These data were obtained from the three automatic stations of air quality monitoring located in the city, in these neighborhoods Belmonte Garden (West of the city), Vila Santa Cecilia (North) and Retiro (central zone). The daily averages for the environmental variables from these stations were calculated after imputing missing data using the modified Expectation Maximization (EM) algorithm, applied under the assumptions of multivariate normal distribution. In addition to the dependence structures between variables, this method also considerate the time-dependent structures of each variable. The temporal component of the contribution of each univariate series was estimated ad hoc way, which is, it took additional models to estimate $\mu_{\mathrm{t}}$. In this imputation, method was implemented to nonparametric cubic spline as estimation option level time series [5].

\subsection{Statistical Analysis}

Initially, were determined the descriptive statistical measurements (average, standard deviation, minimum and maximum values) for the variables total deaths from diseases of the cardiovascular system and for the elderly, and for $\mathrm{PM}_{10}, \mathrm{SO}_{2}, \mathrm{O}_{3}$, low temperature, and $\mathrm{RH}$. The Pearson correlation coefficient was calculated between atmospheric pollutants, the number of hospital admissions and mortality and between climate variables in order to determine whether these data were linearly associated with the significance level of arbitrated $\alpha=20 \%$.

In the time series analysis, daily counts of total deaths orelderly deaths were considered dependent variables $\left(\mathrm{Y}_{\mathrm{t}}\right)$ and the average daily concentrations of $\mathrm{PM}_{10}, \mathrm{SO}_{2}$, and $\mathrm{O}_{3}$, regarded in separate models, were the exposure variables $\left(\mathrm{X}_{1 \mathrm{t}}\right)$ on day $\mathrm{t} ; \mathrm{X}_{\mathrm{it}}$ are the predictor variables, including time, and $\mathrm{S}_{\mathrm{i}}$ are the smoothing functions, according to the equation:

$$
\ln \left(E\left(Y_{t}\right)\right)=l X_{1 t}+\sum_{i=2}^{p} S_{i}\left(X_{i t}\right)
$$

The following control variables were also considered: days of the week, chronological time (index from 1 to $\mathrm{N}$, the last day of the analysis), national and local holidays, and mean daily low temperature $\left({ }^{\circ} \mathrm{C}\right)$ and $\mathrm{RH}(\%)$. In relation to the dependent variable and some control variables, such as meteorological variables, which are not necessarily linear, Generalized Additive Models (GAM) [6] using Poisson regression with non-parametric functions of the cubic smoothing spline type were applied to estimate the association between daily deaths from diseases of the respiratory system and daily levels of these meteorological indicators.

It is noteworthy that a straightened is a function of $\mathrm{X}$ and $\mathrm{Y}$ with the same domain of $\mathrm{X}$, defined for every point $\mathrm{x}_{0}$ or, sometimes, just for $\mathrm{x}_{\mathrm{i}}$ sample. For each value $\mathrm{x}_{\mathrm{i}}$ flatter associates a value $f\left(\mathrm{x}_{\mathrm{i}}\right)$ who's estimated $\hat{f}\left(\mathrm{x}_{\mathrm{i}}\right)$ can be obtained. The values of this function must by definition be "softer" than the $\mathrm{y}$ - 
values, i.e., should have less variability than the values of Y [7].The smoothing procedure was used for the weather and meteorological variable, to adjust the trend and basic seasonal standards and more outstanding long term.

After adjusting the dependent variable for the control factors, the independent variables were inserted one-by-one into the models. Since the biological manifestations of the effects of air pollution on health outcomes apparently display a lag type behavior in individual exposure to pollutants [8], the dependent variables were inserted with a lag time of zero to 10 days, considering the day after exposure, in order for a more precise definition of the model to be used.

The final model's goodness of fit was estimated by residuals analysis outcomes and the Akaike Information Criterion (AIC) [9]. The percentage of relative risks (\%RR) for death that were calculated correspond to a $10 \mu \mathrm{g} / \mathrm{m}^{3}$ increase in the concentration of air pollutants and a $5 \%$ level of significance. This is derived from $\mathrm{RR}$ using the following formula: $\% \mathrm{RR}=\left(\mathrm{e}^{10 \beta}-1\right)^{*} 100$. Data were analyzed for statistical platform $\mathrm{R}$ with ARES and $m$ tsdi statistical library.

\section{RESUlTS AND DISCUSSIONS}

\subsection{Descriptive Analysis of Health Data}

During the study period, 73,536 hospitalizations were registered, which 10,043 (13.66\%) were due to diseases of the cardiovascular system, inside this last group 3,506 (34.91\%) were elderly. Table 1 shows the annual distribution of these hospitalizations for the period.

Table1. Total number of hospital admissions and cardiovascular system diseases, Volta Redonda citizens, RJ, Brazil, from period 2002 to 2006

\begin{tabular}{|l|c|c|c|c|c|c|}
\hline \multirow{2}{*}{ Outcomesvariables } & \multicolumn{5}{|c|}{ Year } & \multirow{2}{*}{ Total } \\
\cline { 2 - 6 } & $\mathbf{2 0 0 2}$ & $\mathbf{2 0 0 3}$ & $\mathbf{2 0 0 4}$ & $\mathbf{2 0 0 5}$ & $\mathbf{2 0 0 6}$ & \\
\hline Total admissions for all cases & 14,751 & 14,330 & 15,314 & 14,237 & 14,904 & $\mathbf{7 3 , 5 3 6}$ \\
\hline $\begin{array}{l}\text { Hospitalizations for cardiovascular } \\
\text { diseases }\end{array}$ & 1,984 & 1,923 & 2,146 & 1,846 & 2,144 & $\mathbf{1 0 , 0 4 3}$ \\
\hline $\begin{array}{l}\text { Hospitalizations for cardiovascular } \\
\text { diseases in elderly }\end{array}$ & 661 & 661 & 730 & 669 & 785 & $\mathbf{3 , 5 0 6}$ \\
\hline
\end{tabular}

* Admissions Data update by DATASUS February $1^{\text {st }}, 2011$

For cardiovascular diseases admissions, for both total and those among the elderly, the averages were respectively $5.50 \pm 3.35$ and $1.92 \pm 1.51$, with a variation between zero and 24 admissions and, between zero and 10 admissions among the elderly (Table 2).

Table2. Descriptive analysis of daily counts of hospital admissions by respiratory (ICD10: J00-99) and cardiovascular system diseases (ICD10:I00-99), in Volta Redonda, Rio de Janeiro, period 2002 to 2006

\begin{tabular}{|l|c|c|c|c|c|c|c|c|}
\hline \multirow{2}{*}{ Variables } & \multicolumn{9}{|c|}{ Descriptors } \\
\cline { 2 - 8 } & $\mathbf{N}$ & $\mathbf{\%}$ & Days & $\mathbf{N A}^{\mathbf{1}}$ & Average & $\mathbf{S D}^{2}$ & Min & Max \\
\hline $\begin{array}{l}\text { Total admissions for } \\
\text { cardiovascular diseases }\end{array}$ & 10,043 & 100 & 1,826 & 0 & 5.50 & 3.35 & 0 & 24 \\
\hline $\begin{array}{l}\text { Hospitalizations for } \\
\text { cardiovascular diseases in } \\
\text { elderly }\end{array}$ & 3,506 & 34.91 & 1,826 & 0 & 1.92 & 1.51 & 0 & 10 \\
\hline
\end{tabular}

Abbreviations: ${ }^{1}$ Not Available $;{ }^{2}$ SD - Standard Deviation; Min-Minimum; Max-Maximum

The Figures 1 and 2describe, respectively, the daily observed and smoothed number of admissions for the cardiovascular system diseases in the total resident population and in elderly people with 65 years or older in Volta Redonda city. The figures show that the highest volume of occurrences is in the winter periods and the curve smoothing spline type does not indicate a long-term trend. A similar pattern of seasonality can be observed in both figures but slight among the elderly. 


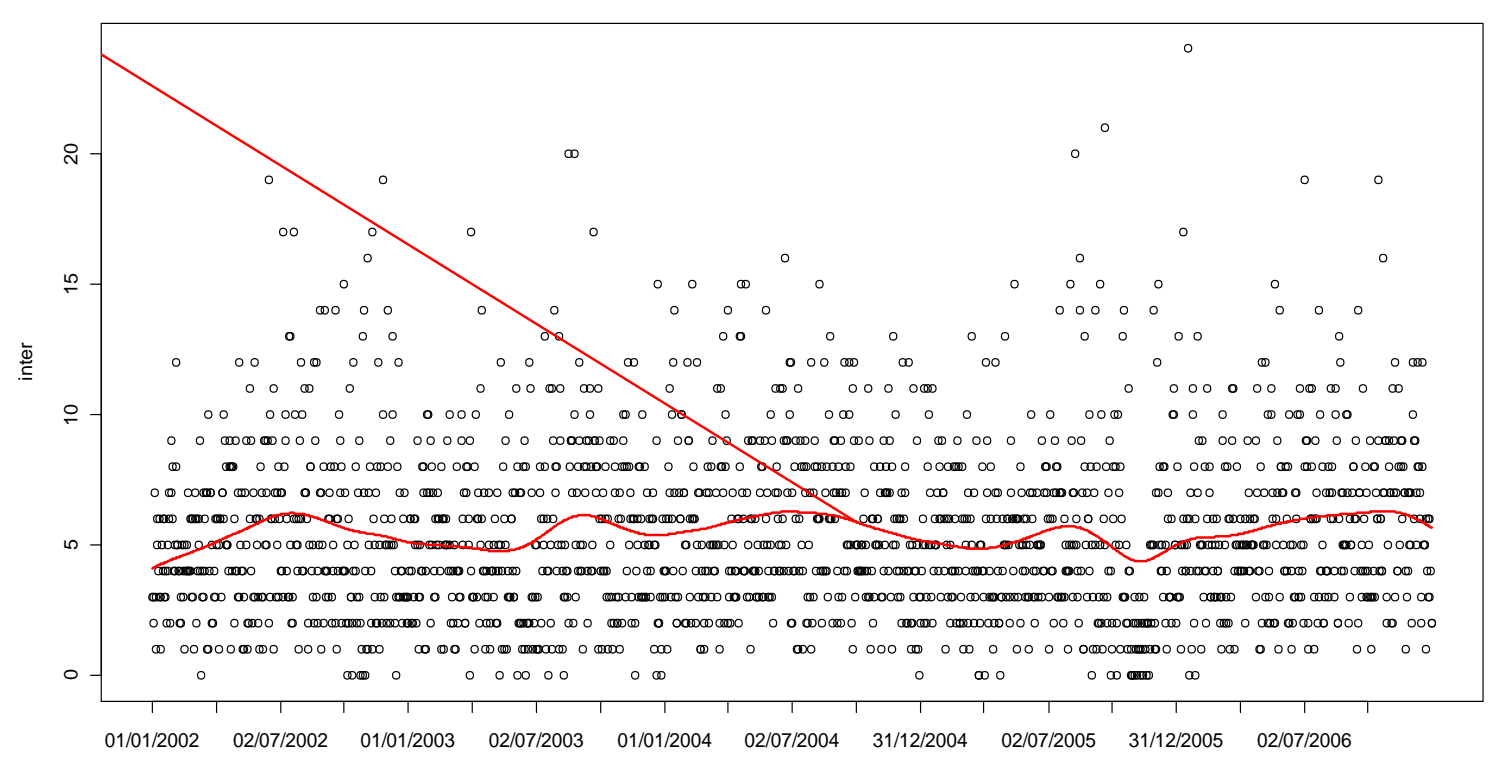

Figure1. Daily distribution of admissions for cardiovascular system diseases and smoothing spline in Volta Redonda city, Rio de Janeiro, Brazil, 2002 to 2006

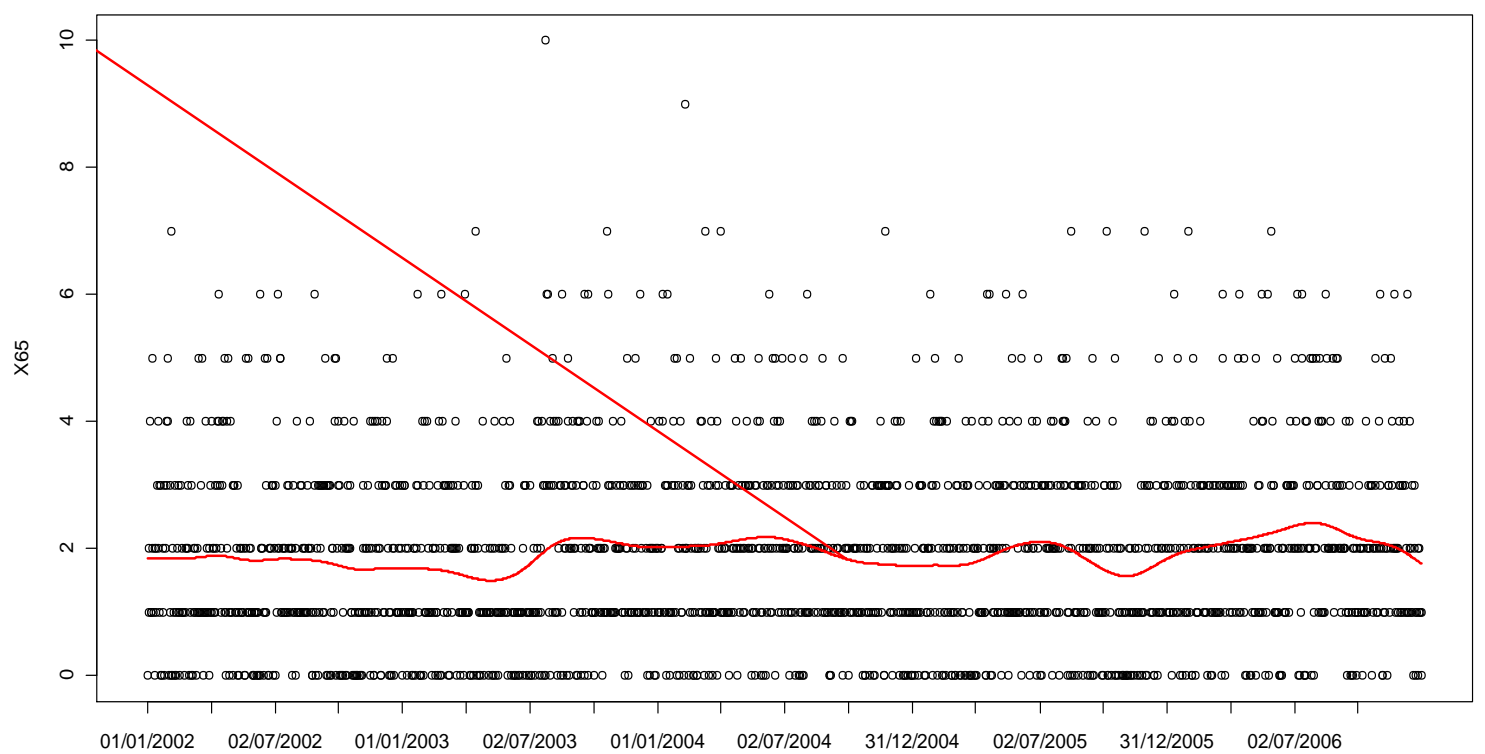

Figure2. Daily distribution of admission in elderly for cardiovascular system diseases and smoothing spline in Volta Redonda city, Rio de Janeiro, RJ, Brazil, 2002 to 2006

\subsection{Descriptive Analysis of Environmental Data}

In the study period, $75 \%$ of the average concentrations of the $\mathrm{PM}_{10}, \mathrm{SO}_{2}$ and $\mathrm{O}_{3}$ daily emissions measured were respectively below $35.95 \mu \mathrm{g} / \mathrm{m}^{3}, 11.47 \mu \mathrm{g} / \mathrm{m}^{3}$ and $75.72 \mu \mathrm{g} / \mathrm{m}^{3}$. The highest mean concentration for each pollutant was $122.70 \mu \mathrm{g} / \mathrm{m}^{3}, 56.50 \mu \mathrm{g} / \mathrm{m}^{3}$ and $171.70 \mu \mathrm{g} / \mathrm{m}^{3}$ (Table 3). The $\mathrm{PM}_{10}$ concentration presented an annual average of $30.56 \pm 12.16 \mu \mathrm{g} / \mathrm{m}^{3}$, below the Brazilian annual emission standards of $50 \mu \mathrm{g} / \mathrm{m}^{3}$ established by CONAMA, through the Resolution legislation number 003/1990. The smoothing curve of the $\mathrm{PM}_{10}$ temporal distribution presented a seasonal pattern with increase of the daily emission levels in the winter period and decrease in the summer, decreasing trend in most of the period and constant at the end (Figure 3a); similar pattern, with lower variation, was observed to $\mathrm{SO}_{2}$ (Figure $3 \mathrm{~b}$ ). $\mathrm{O}_{3}$ presented erratic behavior, seasonality stability and trend from the beginning of the study to September 2004, decreasing trend until April 2005 and increasing trend from this period (Figure $3 \mathrm{c}$ ). $\mathrm{PM}_{10}$ and $\mathrm{SO}_{2}$ did not show a violation of the daily emission standards (average of 24 hours) established at $150 \mu \mathrm{g} / \mathrm{m}^{3}$ and $100 \mu \mathrm{g} / \mathrm{m}^{3}$, respectively. The $\mathrm{O}_{3}$ presented three violations of the standard $\left(161.30,162.10\right.$ and $\left.171.70 \mu \mathrm{g} / \mathrm{m}^{3}\right)$, whose value established by National Council of Environment (CONAMA) for a greater hourly average is $160 \mu \mathrm{g} / \mathrm{m}^{3}$. 


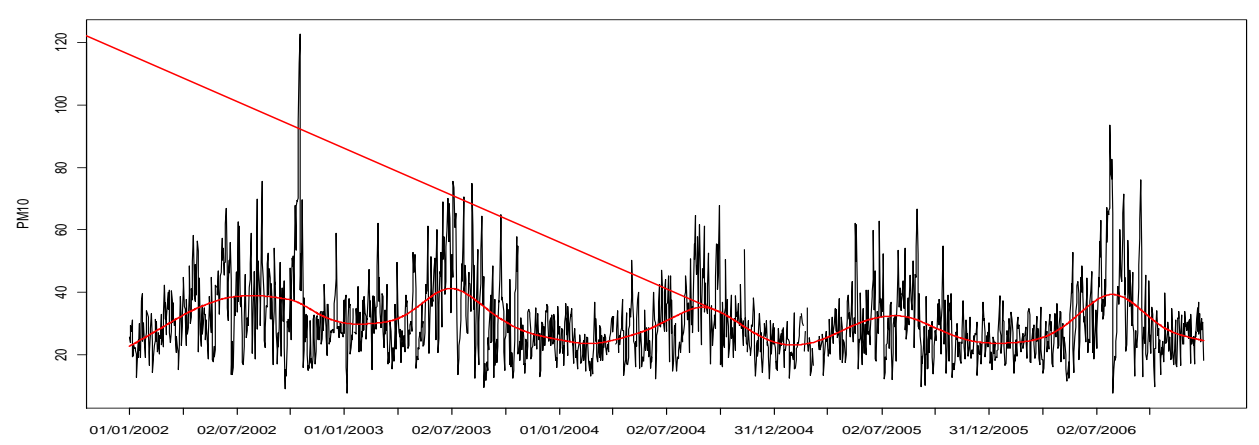

Figure3a. $P M_{10}$ concentration

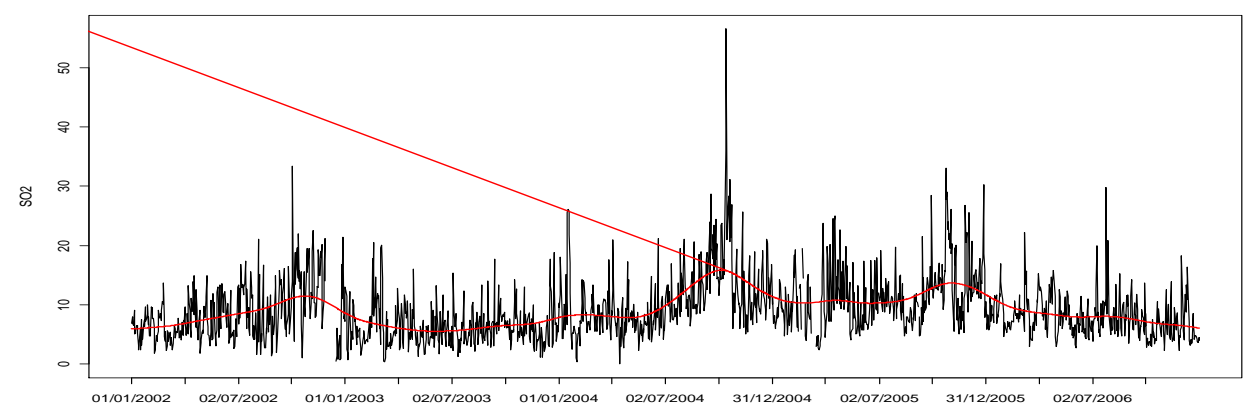

Figure3b. $\mathrm{SO}_{2}$ concentration

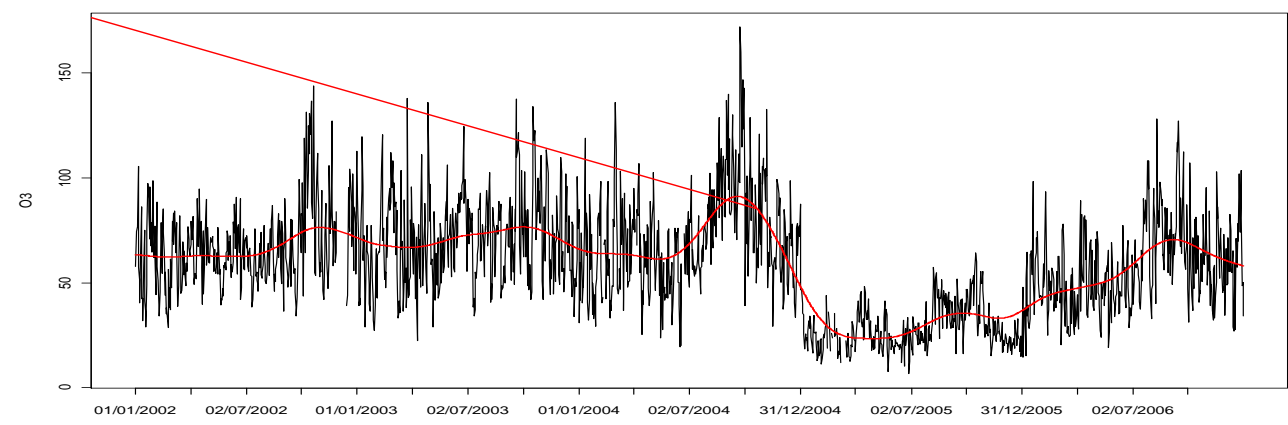

Figure3c. $\mathrm{O}_{3}$ concentration

Figure3. Daily temporal distributionandsmoothingsplineofPM ${ }_{10} \mathrm{SO}_{2}$ e $\mathrm{O}_{3}$ in Volta Redonda city, Rio de Janeiro, Brasil, 2002 a 2006

The averages of relative air humidity and minimum temperature were $81.05 \pm 8.76 \%$ and $18.39 \pm 3.26$ ${ }^{\circ} \mathrm{C}$ (Table 3), respectively.

Table3. Descriptive analysis of daily measurements of $\mathrm{PM}_{10}, \mathrm{SO}_{2}, \mathrm{O}_{3}$ and climatic factors in Volta Redonda, Rio de Janeiro, Brazil, from 2002 to 2006

\begin{tabular}{|l|c|c|c|c|c|c|c|c|c|c|}
\hline \multirow{2}{*}{ Variables } & \multicolumn{10}{|c|}{ Descriptors } \\
\cline { 2 - 11 } & $\mathbf{N}$ & Missing & Days & Average & SD $^{1}$ & Min & Max & P25 & P50 & P75 \\
\hline $\mathrm{PM}_{10}\left(\mu \mathrm{g} / \mathrm{m}^{3}\right)$ & 1,807 & 19 & 1,826 & 30.56 & 12.16 & 7.58 & 122.70 & 22.56 & 27.77 & 35.95 \\
\hline $\mathrm{SO}_{2}\left(\mu \mathrm{g} / \mathrm{m}^{3}\right)$ & 1,794 & 32 & 1,826 & 9.04 & 5.11 & 0.00 & 56.50 & 5.50 & 7.95 & 11.47 \\
\hline $\mathrm{O}_{3}\left(\mu \mathrm{g} / \mathrm{m}^{3}\right)$ & 1,790 & 36 & 1,826 & 59.16 & 25.45 & 6.55 & 171.70 & 40.69 & 57.42 & 75.72 \\
\hline $\mathrm{U} . \mathrm{R} .(\%)$ & 1,763 & 63 & 1,826 & 81.05 & 8.76 & 51.04 & 99.60 & 74.40 & 82.20 & 88.90 \\
\hline $\begin{array}{l}\text { TemperatureMinimum } \\
\left({ }^{\circ} \mathrm{C}\right)\end{array}$ & 1,790 & 36 & 1,826 & 18.39 & 3.26 & 7.37 & 25.45 & 16.20 & 18.87 & 21.03 \\
\hline
\end{tabular}

Abbreviations: ${ }^{\text {SSD }}$ - Standard Deviation; Min - Minimum; Max - Maximum

\subsection{Pearson Correlation Analysis}

The estimated values for the simple correlation coefficient between the health outcomes and the climatic variables and air pollutants evaluated are presented in Table 4. Regarding the statistical significance, at the $20 \%$ level of reliability, a negative correlation between the minimum temperature and all the health outcomes can be observed for climatic variables. For the RH, this correlation was 
positive in relation to the cardiovascular hospitalizations. $\mathrm{PM}_{10}$ presented a positive and significant correlation for most health outcomes, while $\mathrm{SO}_{2}$ presented a positive correlation for the total number of admissions and negative for admissions in the elderly. $\mathrm{O}_{3}$ presented correlation with the total number of the cardiovascular diseases admissions.

Table4. Person correlation for lag zero between health outcomes and environmental variables, Volta Redonda city, RJ, 2002 to 2006

\begin{tabular}{|c|c|c|c|c|c|}
\hline $\begin{array}{ll}\text { Health } & \text { Environmental } \\
\end{array}$ & $\begin{array}{l}\mathbf{P M}_{10} \\
\left(\mu \mathrm{g} / \mathbf{m}^{3}\right)\end{array}$ & $\underset{\left(\mu \mathrm{g} / \mathrm{m}^{3}\right)}{\mathrm{SO}_{2}}$ & $\begin{array}{c}\mathbf{O}_{3} \\
\left(\mu \mathrm{g} / \mathbf{m}^{3}\right)\end{array}$ & $\begin{array}{l}\text { U.R. } \\
(\%)\end{array}$ & TemperatureMinimum $\left({ }^{\circ} \mathbf{C}\right)$ \\
\hline $\begin{array}{l}\text { Total hospital admissions for } \\
\text { cardiovascular diseases }\end{array}$ & $0.034 *$ & 0.014 & $0.039 *$ & 0.024 & $-0.069 *$ \\
\hline $\begin{array}{l}\text { Hospitalizations for } \\
\text { cardiovascular diseases in } \\
\text { elderly }\end{array}$ & $\mathbf{0 . 0 5 3}^{*}$ & -0.024 & 0.009 & 0.022 & $-0.068 *$ \\
\hline
\end{tabular}

$* P$-valor $\leq 20 \%$

\subsection{Regression Analysis}

After adjusting for the confounding factors (days of the week, seasonality and long-term trend, national and municipal holidays, temperature and relative humidity), the variables of the pollutants daily concentrations were introduced in the model one at a time, as well as the lags.

In the analysis of the admissions series by the cardiovascular system diseases, considering all ages, no significant associations were found for the pollutants daily levels $\left(\mathrm{PM}_{10}, \mathrm{SO}_{2}\right.$ and $\left.\mathrm{O}_{3}\right)$, as shown in Figure 4. However, in the admissions series in the elderly aged 65 years and older, it was possible to observe an increase in the admission risk of $3.84 \%$ (95\% CI 0.40 to $7.40 \%$; p-value $=0.03$ ) after three days of exposure to $\mathrm{PM}_{10}$ (Figure 5a). For the daily levels of the other pollutants $\left(\mathrm{SO}_{2}\right.$ and $\left.\mathrm{O}_{3}\right)$ no association was observed with the admission series by cardiovascular diseases in the elderly (Figures $5 \mathrm{~b}$ and $5 \mathrm{c})$.

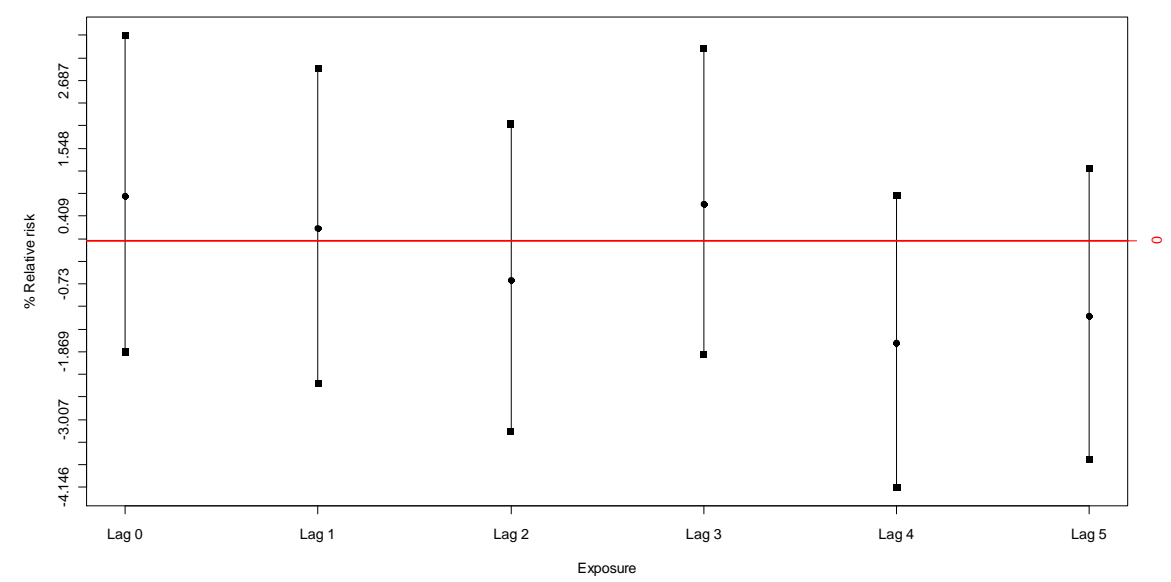

4a. Pollutant: $P M_{10}$ for cardiovascular system diseases cardiovascular

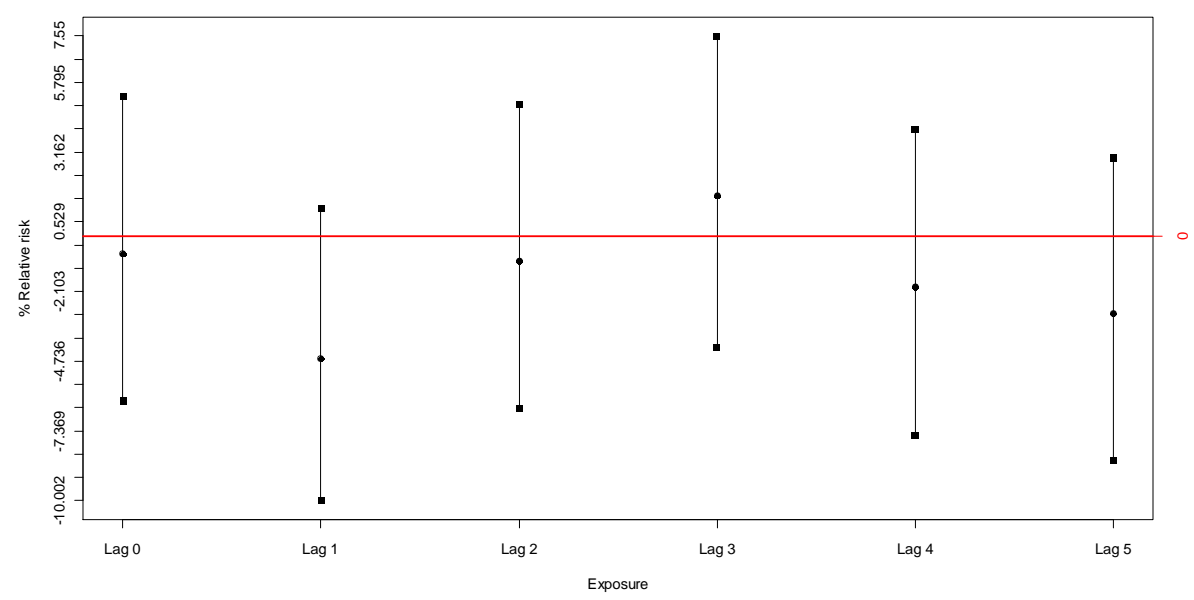

4b. Pollutant: $\mathrm{SO}_{2}$ for total cardiovascular system diseases 


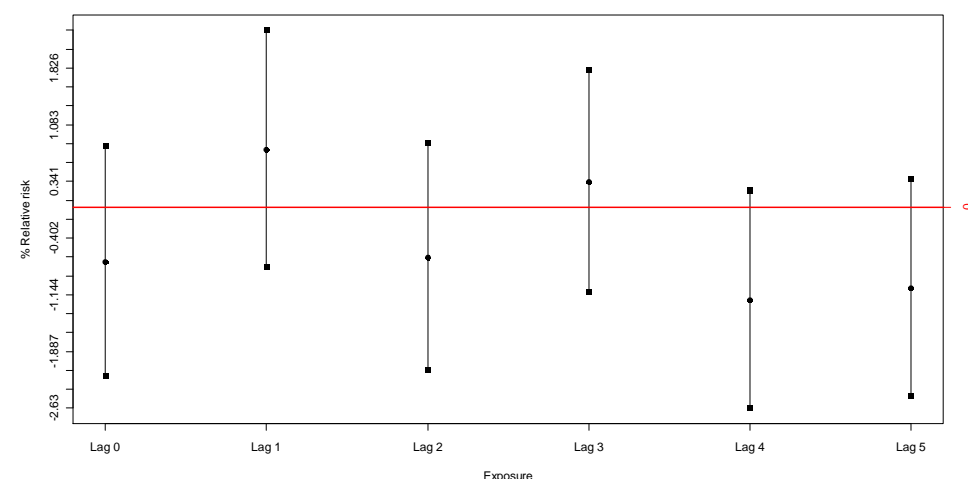

4c. Pollutant: $\mathrm{O}_{3}$ for total cardiovascular system diseases

Figure4. Percentage of relative risk from total admissions for cardiovascular system diseases, for a relative increase of $10 \mu \mathrm{g} / \mathrm{m}^{3}$ in the levels of particulate material $\left(\mathrm{PM}_{10}\right)$, sulfur dioxide $\left(\mathrm{SO}_{2}\right)$ and ozone $\left(\mathrm{O}_{3}\right)$, in Volta Redonda city, Rio de Janeiro, Brazil, 2002 to 2006

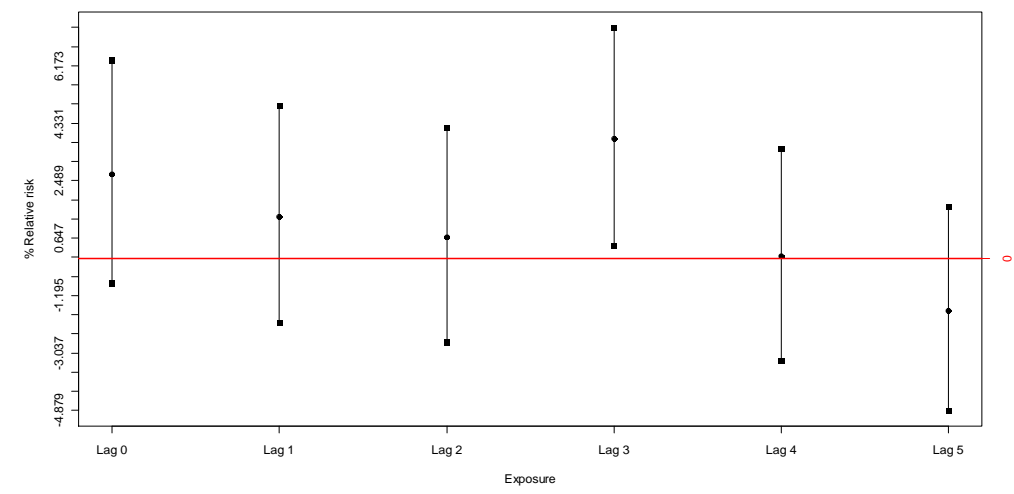

5a. Pollutant: $P M_{10}$ for cardiovascular diseases admissions in elderly people

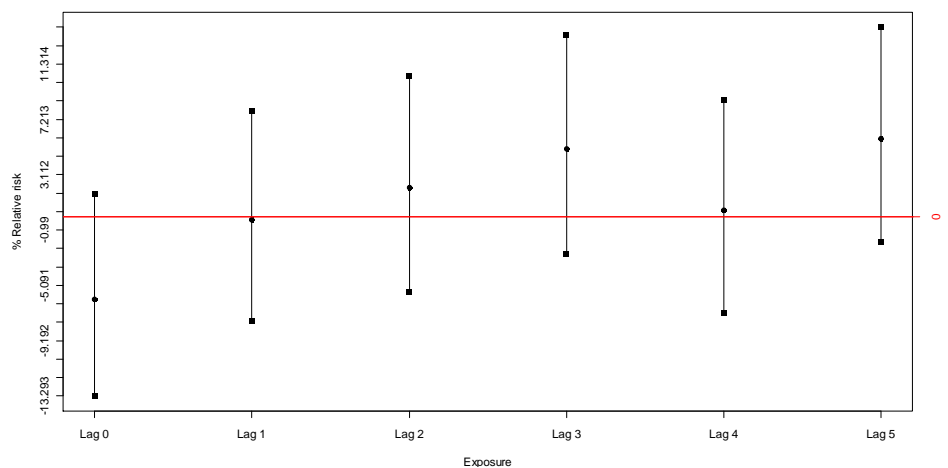

5b. Pollutant: $\mathrm{SO}_{2}$ for cardiovascular diseases admissions in elderly people

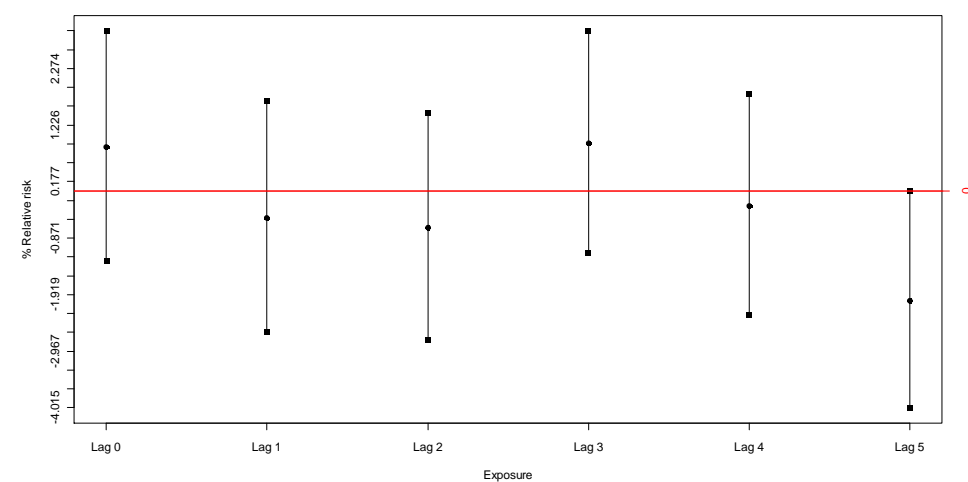

5c. Pollutant: $\mathrm{O}_{3}$ for cardiovascular diseases admissions in elderly people

Figura5. Percentage of relative risk from elderly admissions for cardiovascular system diseases, for relative increase of $10 \mu \mathrm{g} / \mathrm{m}^{3}$ in the levels of particulate material $\left(\mathrm{PM}_{10}\right)$, sulfur dioxide $\left(\mathrm{SO}_{2}\right)$ and ozone $\left(\mathrm{O}_{3}\right)$, in Volta Redonda city, Rio de Janeiro, Brazil, 2002 to 2006 
The diagnosis of the models is presented in Figures 6 and 7. The forecasted value figures indicate that the models reproduce the trend and seasonality of the series. The figures of the residuals over time suggest a good control of the seasonality and do not indicate the occurrence of outliers values. Cook's distance figures also do not indicate the occurrence of outliers. The figures of the partial autocorrelation function indicate slight seasonality or uncontrolled autocorrelation, with a value observed for a six, seven, 12 and 13 day lag (Figure 6) and spurious value observed for a 24 and 25 days lag (Figure 7).
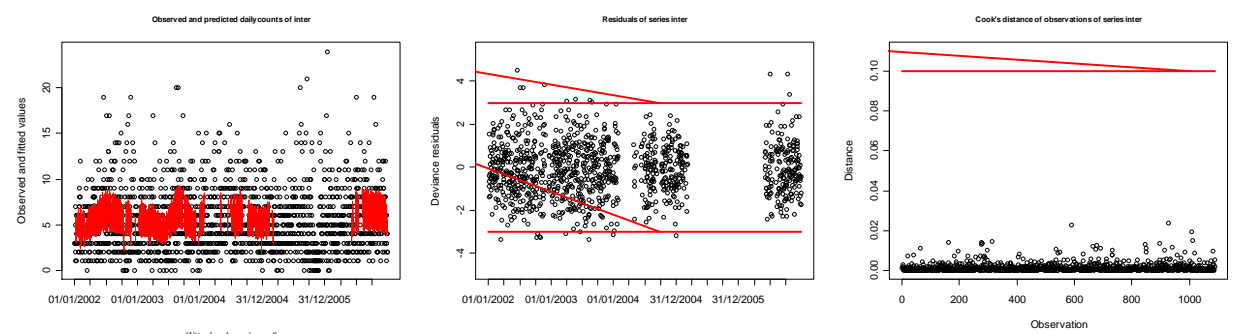

(fitted values in red)

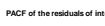
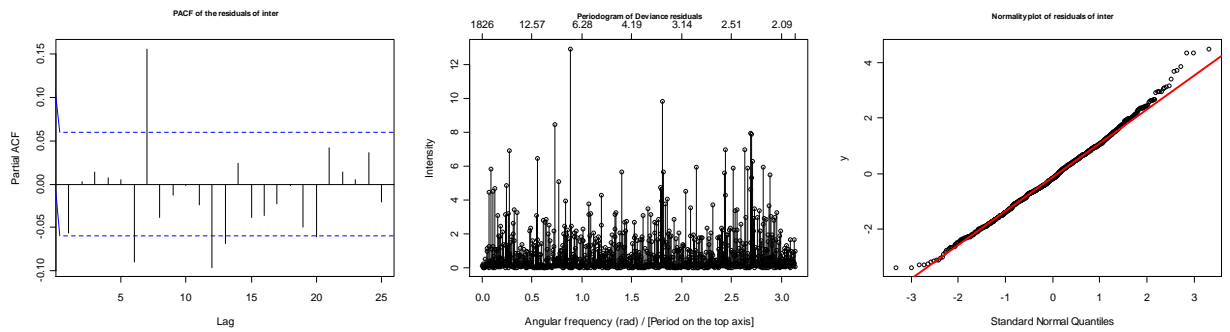

Figure6. Diagnosis of the final baseline model includes known and available confounding factors for the association between air pollution and total hospitalizations for diseases of the cardiovascular system - predicted values, residues versus time, Cook's distance, partial correlation function, Periodogram of residues and quantiles of residues against quantiles of the normal distribution

The residue period grams indicate that there is a slight cyclical variation in the series of total admissions for the cardiovascular diseases system (Figure 6), being properly controlled in the elderly series (Figure 7). The figures of the residues normality do not show a large distance from the residues quantiles in relation to the quantiles of the normal distribution (Figures 6 and 7).
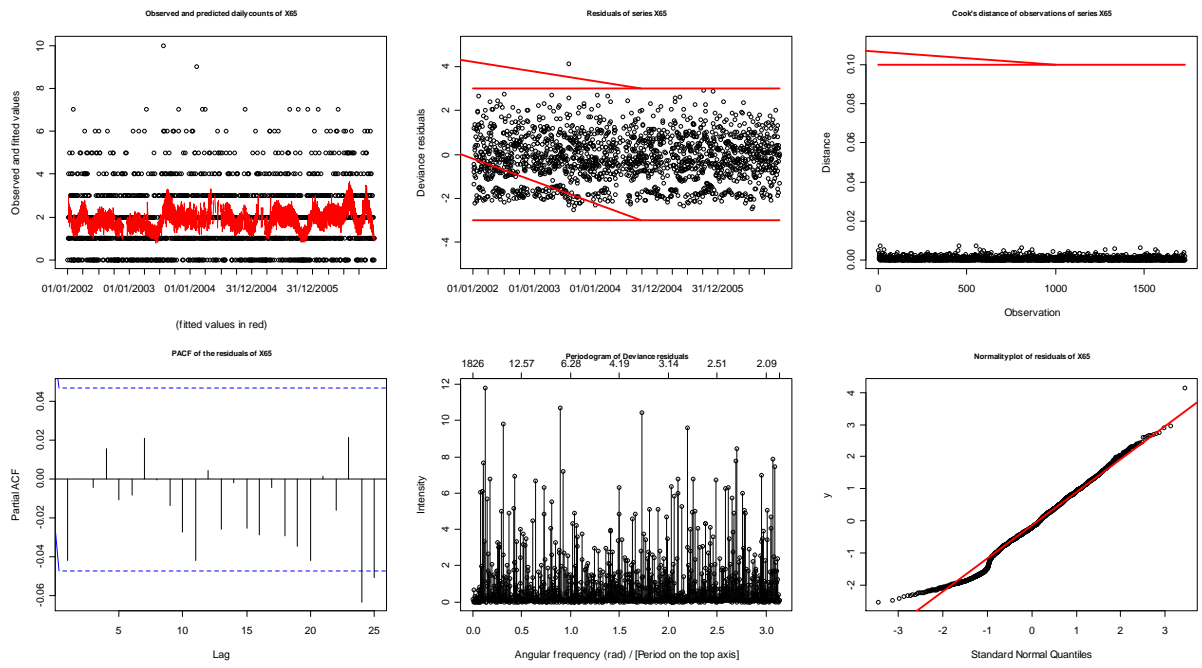

Figure7. Diagnosis of the final baseline model includes known and available confounding factors for the association between air pollution and total hospitalizations in elderly for diseases of the cardiovascular system - predicted values, residues versus time, Cook's distance, partial correlation function, Periodogram of residues and quantiles of residues against quantiles of the normal distribution

Analyzing the results of this study, a positive and significant association between cardiovascular disease in elderly and $\mathrm{PM}_{10}$ can be observed. However, the absence of significant association in the total population does not exclude the possibility of this association exist. According Atkinson et al. [4], an association between $\mathrm{PM}_{10}$ and the increase in cardiovascular deaths and admissions of $2.2 \%$ $(95 \% \mathrm{CI}=0.6-3.8 \%)$ and $0.6 \%(95 \% \mathrm{CI}=0.4-1.7 \%)$, respectively, was found in London. 
Others studies published on cardiovascular [1] and respiratory diseases [2, 3] point out that Volta Redonda city has a high population health risk due to the atmospheric pollutants emissions. In study [1] aimed to evaluate the effects of air pollution on deaths from cardiovascular diseases, the results showed an increase risk of death for an increase of $10 \mu \mathrm{g} / \mathrm{m}^{3}$ of $\mathrm{PM}_{10}$ at lag 2 of 3.67\% (95\%CI: $0.20-$ $7.26 \%$ ) in the total population and 5.23\% (95\%CI: $0.85-9.81 \%)$ for the elderly, respectively [1].

In the other study [2] was observed the increase in risk of hospital admission for respiratory disease from $\mathrm{PM}_{10}$ was $2.67 \%$ (95\% CI: $0.40-5.00 \%$ ) in the total population, $4.15 \%$ (95\% CI: $0.17-8.29 \%$ ) in elderly and $5.22 \%$ (95\% CI: $0.14-10.56 \%$ ) in children. For exposure to $\mathrm{SO}_{2}$, only the total population showed increased risk $6.59 \%$ (95\% CI: $0.76-12.71 \%$ ) [2]. Meanwhile for the mortality from respiratory diseases [3], the increase in risk of deaths from $\mathrm{PM}_{10}$ to lag 1 was $10.01 \%$ (95\% CI: $1.81-18.88 \%$ ) in the total female population and $10.04 \%$ (95\%CI: $0.90-20.02 \%$ ) in elderly women. The increase in risk of deaths from $\mathrm{PM}_{10}$ to lag 9 was $8.25 \%$ in the total male population $(95 \% \mathrm{CI}$ : 0.86-16.18\%) and $10.80 \%$ (95\%CI: 2.18-20.15\%) in elderly men [3]. For exposure to $\mathrm{SO}_{2}$ and $\mathrm{O}_{3}$, the risk was significant in the total male population and the elderly, respectively [3].

According reference[10] when was studying the association between $\mathrm{PM}_{2.5}$ and morbidity and mortality in Prague, Czech Republic, found an increased risk for the cardiovascular admissions ( $R R=$ 1.164, 95\% CI: $1.052-1.287)$ and for the respiratory diseases admissions ( $\mathrm{RR}=1.334,95 \% \mathrm{CI}: 1.126-$ 1.579) for an average of 7 days. These references found no association with mortality data.

Considering the finding of association in cardiovascular deaths[1] and in the others studies in Volta Redonda city [2, 3], the absence of a statistically significant association, in the admissions case, can be related to the database's inconsistencies, related to problems of the information system to which it belongs. The Hospital Admission Orders $(\mathrm{OAH})$ can often present problems related to typing errors and changes in the ICD, the first related to the high turnover of professionals who release this data in the system and/or lack of adequate training; the second due to the need to increase in the financial transfer of the Union to the municipality that rendered the service. In addition, the admissions can often be scheduled or depend on the availability of beds in the network, leading to an error of difficult adjustment in the analysis.

\section{Conclusions}

In Volta Redonda city, the highest concentrations only of $\mathrm{PM}_{10}$ and the hospital admission from cardiovascular diseases occurred in the coolest months. Daily $\mathrm{PM}_{10}$ emissions were associated with hospital admission from cardiovascular diseases, even when emissions were within or close to the standards set by the CONAMA. The association was in especially among the elderly. The risk of hospital admission tended to increase after lag3 of exposure increased. The city presents a degree environmental vulnerability for air pollution what provides an increase in risk for cardiovascular diseases. Therefore, it is necessary to do researches analyzing specific cardiovascular outcomes, looking for helped in the creation of parameters to assess the impact in the environmental health and the intervention actions of government programs.

\section{REFERENCES}

[1] Oliveira MS,Santana MFE, Mattos IE, LEON AP. Air Pollution and Mortality from Cardiovascular Disease in a Population Living near by a Steel Producing Plant in Brazil. JSM Environmental Science \& Ecology 2016, 4 (2): 1029.

[2] Oliveira MS, Santana MFE, Leon AP, Mattos IE. Association between air pollution and hospital admission from respiratory disease: construction of basics parameters to assess the impact of national policy Environmental Health Surveillance related to Air Quality in Brazil. American International Journal of Biology2016, 4(1): 1-19.

[3] Oliveira MS, Leon AP, Mattos IE, KoifmanS. Differential susceptibility according to gender in the association between air pollution and mortality from respiratory diseases. Cad Saúde Pública, 2011. 27 (9): 1827-1836.

[4] Atkinson RW, Fuller GW, Anderson HR, Harrison RM, Armstrong B. Urban ambient particle metrics and health: a time-series analysis. Epidemiology.2010, 21(4): 501-11.

[5] Junger WL, Ponce de Leon A. Imputation of missing data in time series for air pollutants. Atmospheric Environment. 2015, 102: 96-104.

[6] Hastie TJ, Tibshirani RJ. Generalized additive models. New York: Chapman and Hall. 1990, 43: 87. 
[7] Conceição GMS, Saldiva PHN, Singer JM. Modelos MLG e MAG para análise da associação entre poluição atmosférica e marcadores de morbi-mortalidade: uma introdução baseada em dados da cidade de São Paulo. Rev. Bras. Epidemiol.2001, 4(3): 206-219.

[8] Braga AL, Zanobetti A, Schwartz J. The lag structure between particulate air pollution and respiratory and cardiovascular deaths in 10 US cities. J Occup Environ Med. 2001, 43: 927-933.

[9] Akaike H, Petrov BN, Csaki F. Information theory as an extension of the maximum likelihood principle. Second International Symposium on Information Theory. Budapest: Akade' miai Kiado’. 1973, 267-281.

[10] Braniš M, Vyškovská J, Malý M, Hovorka J. Association of size-resolved number concentrations of particulate matter with cardiovascular and respiratory hospital admissions and mortality in Prague, Czech Republic. InhalToxicol. 2010, 22 (2):21-8. 